\title{
ORCID og OJS
}

\section{ORCID \\ and Researchers}

OJS kan med den nye version 2.4.5 håndtere Open Researcher and Contributor ID (ORCID).

ORCID er et unikt ID, som den enkelte forsker får ved at lade sig registrere på ORCID's hjemmeside - www.orcid.org.

Ved at tilknytte en ORCID ID til sine udgivelser sikrer man, at andre ikke fejlagtigt krediteres for ens arbejde, og det vil med tiden blive lettere at udarbejde litteraturlister og anden dokumentation, der eksempelvis kan bruges i forbindelse med fondsansøgninger. ORCID beskriver selv fordelene på organisationens hjemmeside http://orcid.org/about/what-is-orcid og på Vimeo:

http://vimeo.com/97150912

ORCID udveksler data med en række danske uddannelses- og forskningsinstitutioner. Heriblandt Aalborg Universitets og Aarhus Universitets PURE databaser. Det må forventes, at flere danske forskningsinstitutioner bliver tilknyttede. Se listen her:

http://orcid.org/organizations/integrators/current.

På grund af fordelene for forfatterene vil vi anbefale alle redaktioner, der udgiver tidsskrifter via Statsbibliotekets og Aarhus University Library's OJS-server, at tilskynde forfatterne til at lade sig registrere hos ORCID og efterfølgende angive deres ORCID ID, når de indsender deres artikler.

ORCID ID'et kan indskrives, når den enkelte forfatter opretter sig som bruger i OJS. Er forfatteren i forvejen registreret på OJS-serveren, kan man tilføje ORCID til de eksisterende brugerdata. Når en forfatter indsender sit manuskript kan denne ligeledes tilføje ORCID hos eventuelle medforfattere.

Det er ikke et krav at anvende ORCID. 
Er man allerede registreret som bruger i OJS, tilføjer man blot sin ORCID ID til den eksisterende profil. Det gøres ved at logge ind og vælge 'My profile'/'Min profil' i sidemenuen. Derved fremkommer siden 'Edit profile'/'Redigér profil', hvor feltet ORCID ID udfyldes. Afslutningsvis skal man huske at klikke på "Gem" nederst på siden.

\begin{tabular}{|c|c|}
\hline \multicolumn{2}{|l|}{ Edit Profile } \\
\hline Form Language & English Submit \\
\hline & To enter the information below in additional languages, first select the language. \\
\hline \multicolumn{2}{|r|}{ - } \\
\hline First Name * & Niels \\
\hline Middle Name & Erik \\
\hline Last Name * & Frederiksen \\
\hline Gender & \\
\hline Initials & Joan Alice Smith = JAS \\
\hline Username & admin \\
\hline \multicolumn{2}{|l|}{ Password } \\
\hline \multirow{4}{*}{ Repeat password } & The password must be at least 6 characters. \\
\hline & \\
\hline & $\begin{array}{l}\text { The password must be at least } 6 \text { characters. } \\
\text { Leave the password fields blank to keep the current password. }\end{array}$ \\
\hline & $\square$ Require the user to change their password the next time they log in. \\
\hline \multirow[t]{2}{*}{ Affiliation } & 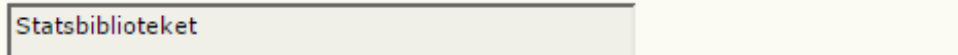 \\
\hline & (Your institution, e.g. "Simon Fraser University") \\
\hline \multicolumn{2}{|r|}{ ( } \\
\hline \multirow[t]{2}{*}{ Email * } & nef@statsbiblioteket.dk \\
\hline & http://orcid.org/0000-0002-6281-9981 \\
\hline URL & \\
\hline Phone & +4589462179 \\
\hline
\end{tabular}


ORCID ID-feltet vil herefter automatisk være udfyldt, når forfatteren når frem til upload-siden, hvor metadata indskrives:

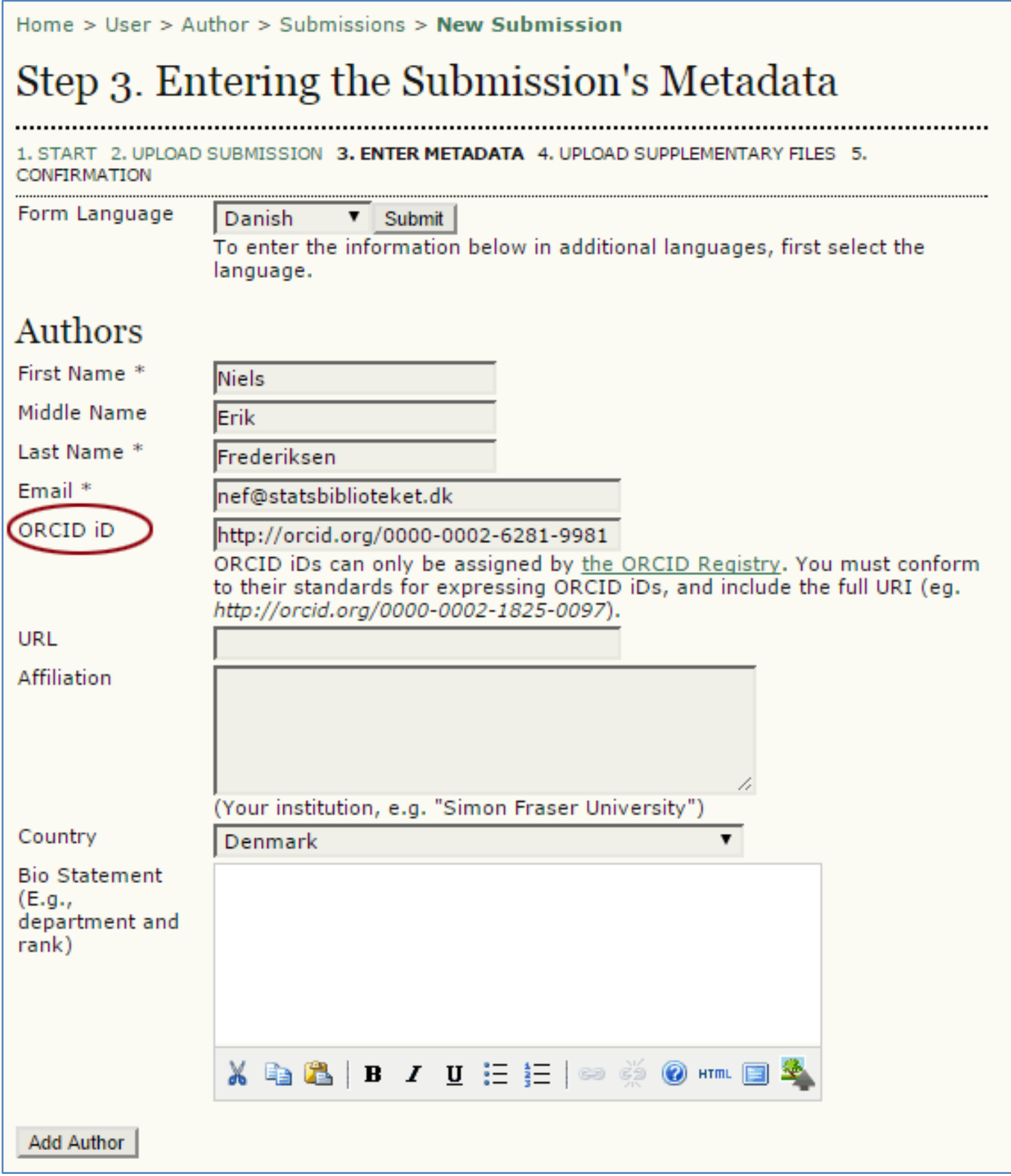


I løbet af submission-processen vil det være muligt for forfatteren at registrere sine medforfattere. Det sker ved at klikke på 'Add Author'/'Tilføj forfatter':

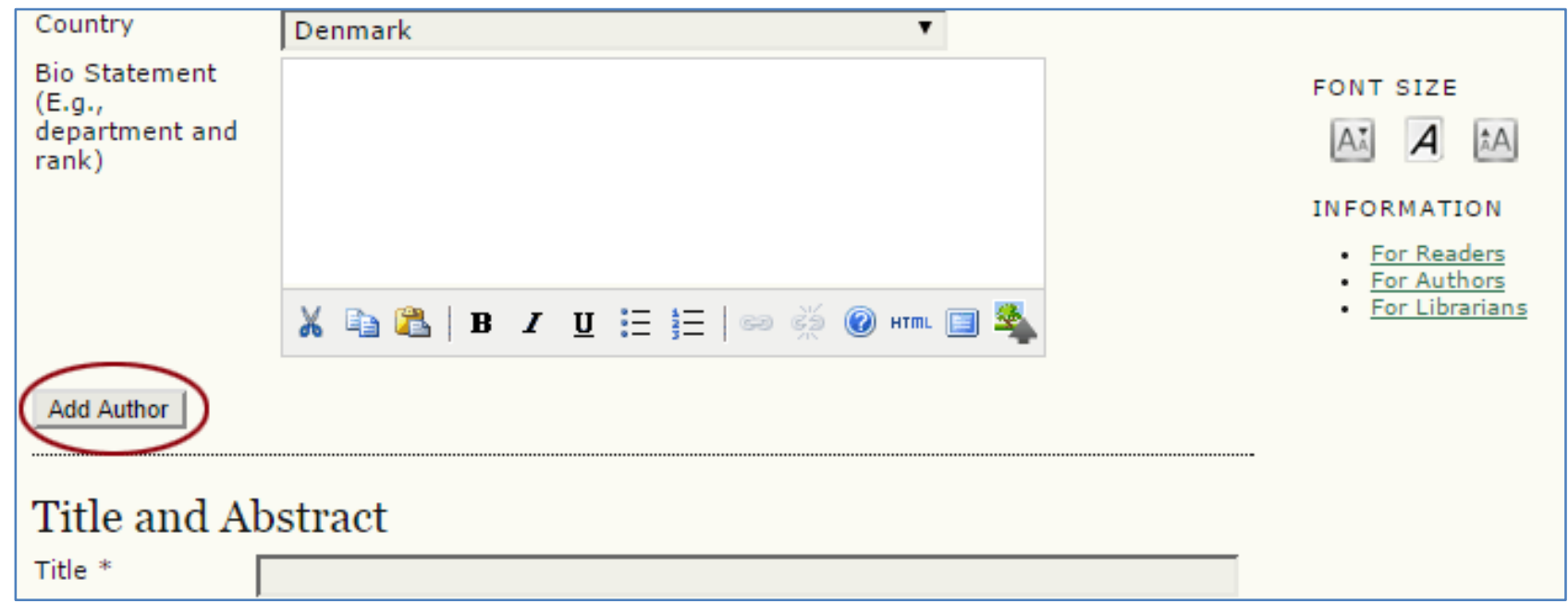

Skærmen ændrer sig og man kan nu tilføje alle oplysninger om sine medforfattere, herunder ORCID.

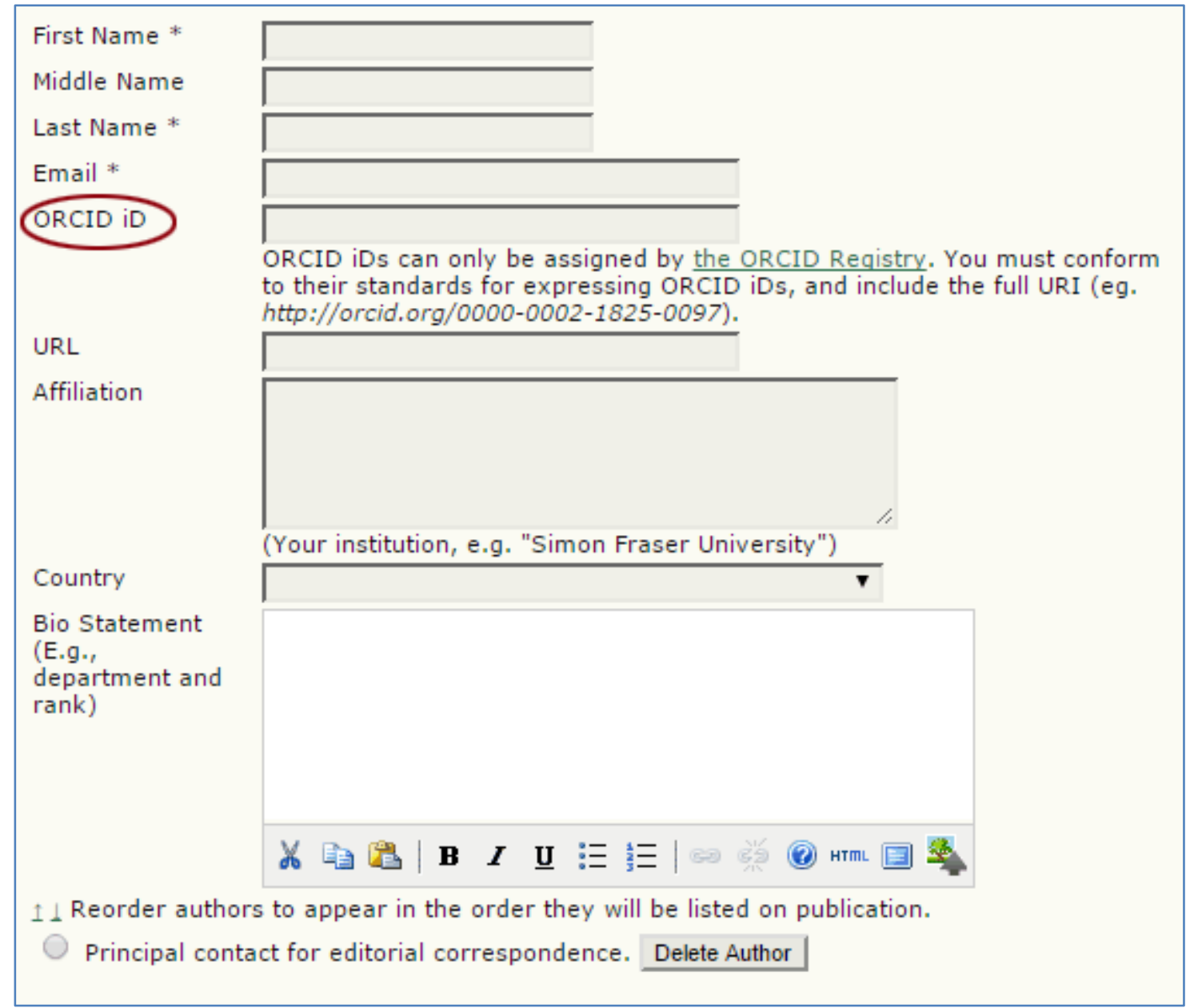


Bruger man 'QuickSubmit Plug-innen' til at uploade artikler, er det desværre endnu ikke muligt, at tilknytte ORCID ID til forfatterne via denne plug-in. Dette vil PKP, der står bag OJS-softwaren, udbedre i næste udgave. Redaktøren kan dog efterfølgende tilføje ID'et på 'Summary/Resumésiden' under 'Edit metadata/Redigér metadata'

\section{Submission Metadata}

\section{EDIT METADATA}

\section{Authors}

Name

Niels Erik Frederiksen $\cong$

Affiliation

Statsbiblioteket

Country

Denmark

Bio Statement

Principal contact for editorial correspondence.

\section{Title and Abstract}

Jesper B. Thestrup og Niels Erik Frederiksen 